\title{
Detection of AIO molecules produced by KrF laser-ablated Al atoms in oxygen gas and plasma environments
}

\author{
C. H. Ching, a) R. M. Gilgenbach, ${ }^{\text {b) }}$ and J. S. Lash \\ Intense Energy Beam Interaction Laboratory, Nuclear Engineering Department, University of Michigan, \\ Ann Arbor, Michigan 48109-2104
}

(Received 9 January 1995; accepted for publication 14 May 1995)

\begin{abstract}
Experiments have been performed to measure, in real time, the formation of AlO molecules from laser-ablated $\mathrm{Al}$ atoms in oxygen gas and plasma environments. The $\mathrm{Al}$ atom plume is generated by focusing a $\mathrm{KrF}$ laser $\left(4 \mathrm{~J} / \mathrm{cm}^{2}\right)$ on $\mathrm{Al}$ metal targets or polycrystalline $\mathrm{Al}_{2} \mathrm{O}_{3}$ (alumina) ceramic. $\mathrm{AlO}$ molecule formation has been characterized by emission spectroscopy at 464.82 and $484.22 \mathrm{~nm}$ molecular bandheads. Time-integrated and time-resolved optical emissions have been measured of laser-ablated $\mathrm{Al}$ atoms interacting with oxygen or argon neutral-gas versus plasma backgrounds generated by a high-voltage capacitive discharge. Results indicate that gas/plasma-phase reactions occur between laser-ablated $\mathrm{Al}$ atoms and oxygen. Optimal enhancement of AlO optical emission is measured in oxygen plasmas at about 200 mTorr fill pressure. (C) 1995 American Institute of Physics.
\end{abstract}

\section{INTRODUCTION}

Laser ablation has proven to be an important technique for thin-film deposition and micromachining of metals, ceramics (metal nitrides, ${ }^{1}$ metal oxides ${ }^{2}$ ), crystals, ${ }^{3}$ and polymers. ${ }^{4}$ Researchers have employed gas ${ }^{5}$ (at 100-200 mTorr to atmospheric ${ }^{6}$ pressure) and plasma ${ }^{7}$ backgrounds to maintain the stoichiometry in deposition of metal-nitride and metal-oxide films. It is important to measure gas-phase and plasma-phase chemical oxidation reactions of laser-ablated metals, in order to understand the effects of these environments on thin-film deposition.

In this article, we present real-time measurements of $\mathrm{AlO}$ molecule production from oxidation of laser-ablated $\mathrm{Al}$ atoms in oxygen gas and plasma for comparison versus argon plasma environments.

\section{EXPERIMENTAL CONFIGURATION}

The laser-ablation experimental configuration is depicted in Fig. 1. A KrF laser ( $40 \mathrm{~ns}$ pulselength) is focused at normal incidence (at fluences of $-4 \mathrm{~J} / \mathrm{cm}^{2}$ ) on a target of $\mathrm{Al}$ metal $\left(98.5 \%\right.$ pure) or $\mathrm{Al}_{2} \mathrm{O}_{3}(99.7 \%$ pure polycrystalline, alumina ${ }^{8}$ ) ceramic in a six-way, turbomolecular-pumped vacuum chamber. Gases $\left(\mathrm{O}_{2}\right.$ or $\left.\mathrm{Ar}\right)$ were fed into the chamber by a static fill, with pressures measured by an MKS Baratron capacitance manometer. In the present experiments, a set of two high-voltage electrodes (2-cm-diam copper disks) were arranged on either side of the ablation plume (1.2 $\mathrm{cm}$ apart). The distance from the center of the electrodes to the target surface was $3.5 \mathrm{~cm}$. The capacitor bank was configured in a three-stage artificial transmission line, ${ }^{9}$ which gives a voltage flattop of $2 \mu \mathrm{s}$ duration into a matched load; ${ }^{10}$ in the unmatched loads of the plasma discharge here, the pulse gave ringing at later times, out to $\sim 30 \mu \mathrm{s}$. The peak voltage $(\sim 2500 \mathrm{~V})$ and current $(160 \mathrm{~A})$ output of this

a) Present address: Sandia National Laboratories, Albuquerque, NM 87185.

b) Author to whom correspondence should be addressed. capacitor bank in these experiments delivered up to 0.2-0.4 MW peak of ohmic heating power to the plasma discharge.

Optical emission spectroscopy was performed by two systems: (1) a $0.25 \mathrm{~m}$ spectrograph-optical-multichannelanalyzer system, which measures the entire spectrum during a gate pulse, and (2) a $0.25 \mathrm{~m}$ monochromatorphotomultiplier-tube system, which measures the temporal evolution of a single wavelength.

\section{RESULTS AND DISCUSSION}

Our previous experiments ${ }^{11,12}$ utilized resonantholographic interferometry (on the $394.4 \mathrm{~nm} \mathrm{Al}$ ground state, neutral line) to measure the line density of $\mathrm{Al}$ neutral atoms ablated from $\mathrm{Al}$ metal targets and $\mathrm{Al}_{2} \mathrm{O}_{3}$ targets. These measurements gave peak Al-atom line densities of $10^{14} \mathrm{~cm}^{-2}$ (for $\mathrm{Al}$ targets) and $2 \times 10^{15} \mathrm{~cm}^{-2}$ (for alumina targets). The total number of ablated neutral $\mathrm{Al}$ atoms was about $10^{14}$ (from $\mathrm{Al}$ ) and $10^{15}$ (from alumina). ${ }^{11,12}$ The higher density of ablated $\mathrm{Al}$ atoms from $\mathrm{Al}_{2} \mathrm{O}_{3}$ was believed due to the lower reflectivity and lower thermal conductivity ${ }^{13}$ of the alumina.

The emission from AlO molecular bandheads were measured at $464.82\left(\nu^{\prime}=1, \nu^{\prime \prime}=0\right)$ and $484.22 \mathrm{~nm}\left(\nu^{\prime}=0, \nu^{\prime \prime}=0\right)$ to monitor the relative density of molecule production. Figure 2 shows the time-integrated spectrum of KrF laserablated aluminum metal in oxygen plasma at a fill pressure of 200 mTorr. The AlO molecular bandheads' optical emission at 464.82 and $484.22 \mathrm{~nm}$ are prominent, demonstrating that $\mathrm{AlO}$ molecule production is occurring from $\mathrm{Al}$ atoms in the oxygen plasma environment. For Al metal ablation, AlO molecular emission is strong in the oxygen plasma; however, AlO emission is below the detectability noise level for either the oxygen gas or argon gas/plasma. Since the optical emission is excited primarily by plasma electrons, the oxygen and argon plasmas would have similar excitation of existing AlO molecular populations. Therefore, it can be concluded that significant AlO molecule production takes place in the oxygen plasma. 


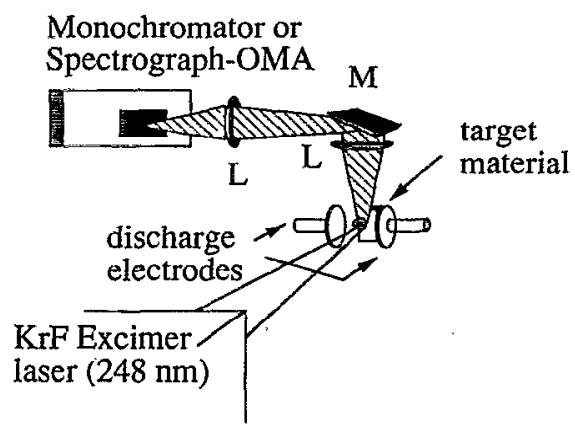

FIG. 1. Experimental configuration.

Because the ablated $\mathrm{Al}$ atom density from $\mathrm{Al}_{2} \mathrm{O}_{3}$ targets was 10-20 times higher than from $\mathrm{Al}$ metal, ${ }^{11}$ ablation of $\mathrm{Al}_{2} \mathrm{O}_{3}$ allowed comparison of $\mathrm{AlO}$ molecular emission in oxygen gas for comparison to plasma environments (Figs. 3 and 4).

Figure 3 shows the time-resolved $\mathrm{AlO}$ emission (observed at $464.82 \mathrm{~nm}$ bandhead) from laser-ablated alumina ceramic as a function of oxygen gas pressure. (The first peak is due to laser-plasma light.) The second peak represents AlO molecular emission from gas-phase reactions. It is seen that the second (AlO) peak emission intensity increases with background oxygen pressure; no such second peak is observed with argon background, verifying gas-phase production of AlO molecules. The AlO optical emission in the oxygen plasma at 200 mTorr, shown in Fig. 3(g), is about twice that of the gas [Fig. 3(c)] at the same pressure. Peak AlO optical emission occurs near the peak discharge voltage. AlO optical emission continues at late times (out to $30 \mu \mathrm{s}$ ) due to ringing of the capacitive discharge.

Figure 4 summarizes the peak in the temporally resolved AlO molecular ( $464.82 \mathrm{~nm}$ bandhead) optical emission data from laser-ablated alumina ceramic in oxygen gas versus plasma, as a function of fill-gas pressure (as in the second peaks in Fig. 3). It is seen that the temporally resolved AlO

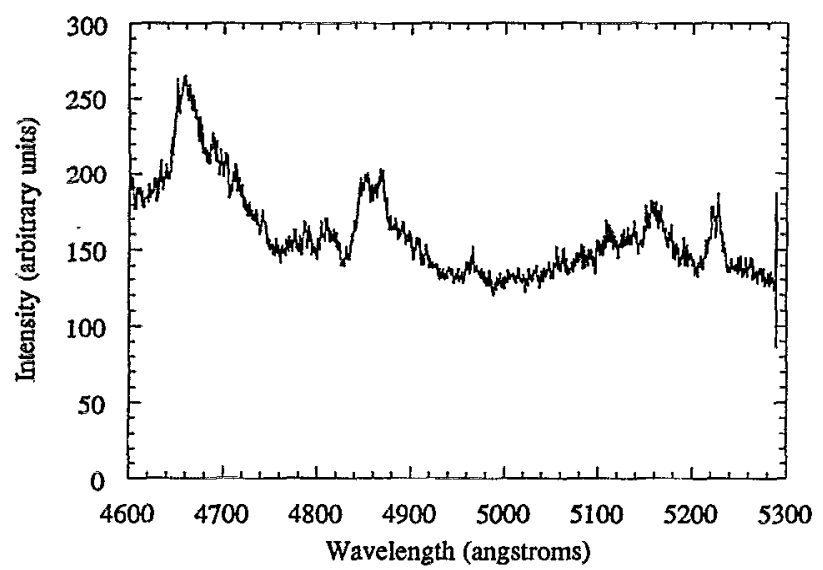

FIG. 2. Optical emission spectrum (time-integrated) from $\mathrm{KrF}$ laser ablation of aluminum metal in oxygen plasma at $200 \mathrm{~m}$ Torr fill pressure. Spectrum is single-pulse without background subtraction; gatewidth $=7 \mu$ s.

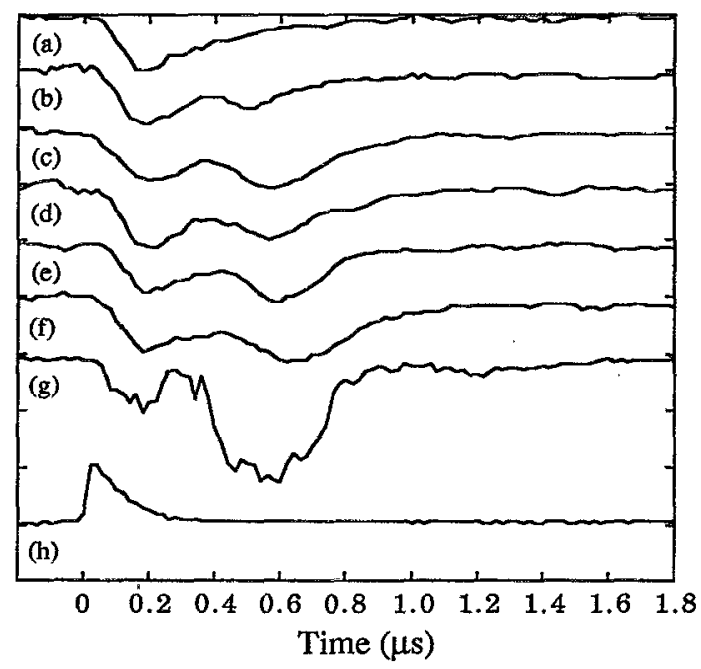

FIG. 3. Time-resolved optical emission signals ( $150 \mathrm{mV} / \mathrm{div})$ of AIO molecules ( $464.82 \mathrm{~nm}$ bandhead) from laser-ablated alumina in environments: (a) oxygen gas at $50 \mathrm{mT}$ Torr; (b) oxygen gas at $100 \mathrm{~m}$ Torr; (c) oxygen gas at 200 mTorr; (d) oxygen gas at 300 mTorr; (e) oxygen gas at 500 mTorr; (f) oxygen gas at $800 \mathrm{mT}$ Torr; $(\mathrm{g})$ oxygen capacitive-discharge plasma at fill pressure of $200 \mathrm{~m}$ Torr; (h) silicon photodiode signal from $40 \mathrm{~ns} \mathrm{KrF}$ excimer laser pulse (tail is due to detector response). Digital (8-bit) smoothing has been applied to reduce noise.

molecule emission is optimized, for the oxygen capacitivedischarge plasma over the gas, at the fill pressure of 200 mTorr. This is roughly the pressure which many researchers have chosen as optimal for deposition of metal-oxide (and metal-nitride) thin films in gas backgrounds. At higher-thanoptimal pressures, the gas-case $\mathrm{AlO}$ emission is comparable to the plasma emission.

The emission of the $394.4 \mathrm{~nm}$ atomic Al line (from $\mathrm{Al}_{2} \mathrm{O}_{3}$ ablation) was also measured versus time and was generally lower (at $t<20 \mu \mathrm{s}$ ) in oxygen plasmas than argon plasmas, indicating $\mathrm{Al}$ depletion, again, caused by reaction of $\mathrm{Al}$ atoms with plasma oxygen.

The above data supports the belief that the plasma discharge generates dissociated (atomic) oxygen and radicals,

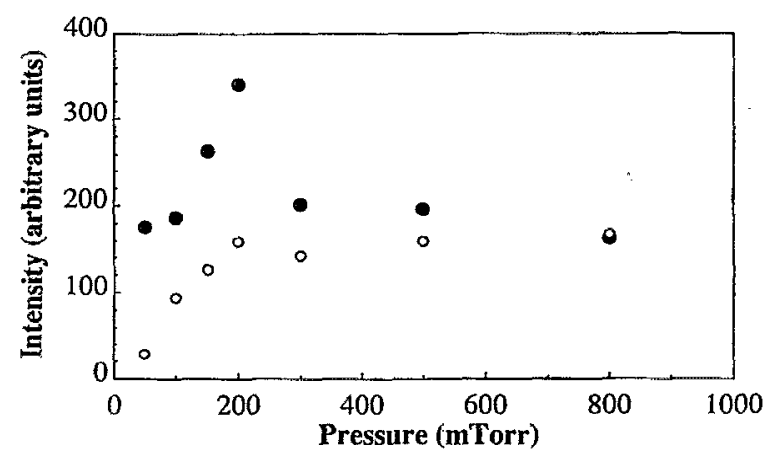

FIG. 4. Peak of time-resolved optical emission from AlO molecules (464.82 $\mathrm{nm}$ bandhead) from laser-ablated alumina in oxygen gas (open circles) vs capacitive-discharge plasma (solid circles). Single pulse data of the second temporal peak. 
which enhance the $\mathrm{Al}$ oxidation reaction rate to produce $\mathrm{AlO}$ molecules.

\section{ACKNOWLEDGMENTS}

This research was supported by National Science Foundation Grant No. CTS-9108971. J. S. L. acknowledges a National Science Foundation Graduate Fellowship.

${ }^{1}$ A. K. Balla, L. Salamanca-Riba, G. L. Doll, C. A. Taylor, and R. Clarke, J. Mater. Res. 7, 1618 (1992).

${ }^{2}$ D. B. Geohegan, MRS Proc. 285, 27 (1993).

${ }^{3}$ M. Affatigato, K. Tang, R. Haglund, and C. H. Chen, Appl. Phys. Lett. 65, 1751 (1994).

${ }^{4}$ R. Srinivasan, J. Appl. Phys. 73, 2743 (1993).
${ }^{5}$ H. Wang, A. P. Salzberg, and B. R. Weiner, Appl. Phys. Lett. 59, 935 (1991).

${ }^{6}$ P. Engst, P. Kubat, P. Bohacek, and J. Wild, Appl. Phys. Lett. 64, 2025 (1994).

${ }^{7}$ T. P. Chen, T-I. Bao, and I. Lin, Appl. Phys. Lett. 63, 2475 (1993).

${ }^{8}$ Johnson-Matthey Co., P. O. Box 8247, Ward Hill, MA 01835-0747.

${ }^{9}$ G. N. Glasoe and J. V. I ebacq7, Pulse Generators (McGraw-Hill, New York, 1948).

${ }^{10}$ J. S. Lash, R. M. Gilgenbach, and C. H. Ching, Appl. Phys. Lett. 65, 531 (1994).

${ }^{11}$ R. A. Lindley, R. M. Gilgenbach, and C. H. Ching, Appl. Phys. Lett. 63, 888 (1993); also R. A. Lindley, R. M. Gilgenbach, C. H. Ching, and J. S. Lash, J. Appl. Phys. 76, 5457 (1994).

${ }^{12}$ R. M. Gilgenbach, C. H. Ching, J. S. Lash, and R. A. Lindley, Phys. Plasmas 1, 1619 (1994).

${ }^{13} \mathrm{G}$. L. Doll (private communication). 